\title{
Endoscopic endonasal pituitary gland hemi-transposition for resection of a dorsum sellae meningioma
}

\author{
Alaa S. Montaser, MD, ${ }^{1,2}$ Juan M. Revuelta Barbero, MD, ${ }^{1}$ Alexandre Todeschini, MD, ${ }^{1}$ \\ André Beer-Furlan, MD, ${ }^{3}$ Russell R. Lonser, MD, ${ }^{1}$ Ricardo L. Carrau, MD, ${ }^{4}$ \\ and Daniel M. Prevedello, MD1,4
}

1Department of Neurological Surgery, Wexner Medical Center, The Ohio State University College of Medicine, Columbus, Ohio; 2Department of Neurological Surgery, Ain Shams University, Cairo, Egypt; ${ }^{3}$ Department of Neurological Surgery, Rush University Medical Center, Chicago, Illinois; and 'Department of Otolaryngology-Head and Neck Surgery, Wexner Medical Center, The Ohio State University College of Medicine, Columbus, Ohio

\begin{abstract}
A 69-year-old female with incidental diagnosis of a dorsum sellae meningioma had shown significant tumor growth after initial conservative management. The procedure started with a microscopic sublabial transsphenoidal approach to the sella and the suprasellar space. Due to limitations to a safe dissection and removal of the retrosellar component, the surgery was converted to a purely endoscopic endonasal approach with left hemi-transposition of the pituitary gland, followed by drilling of the dorsum sellae and removal of the left posterior clinoid process. A complete tumor resection was achieved, and a multilayer skull base reconstruction was performed without complications.
\end{abstract}

The video can be found here: https://youtu.be/BEolyK-To_A.

KEYWORDS dorsum sellae; meningioma; hemi-transposition; endoscopic endonasal

SUBMITTED July 13, 2017. ACCEPTED August 2, 2017.

INCLUDE WHEN CITING Published online October 1, 2017; DOI: http://thejns.org/doi/abs/10.3171/2017.10.FocusVid.17344.

CORRESPONDENCE Daniel M. Prevedello, Department of Neurological Surgery, The Ohio State University Wexner Medical Center, 410 W 10th Ave., N-1049 Doan Hall, Columbus, OH 43210. email: dprevedello@gmail.com. 